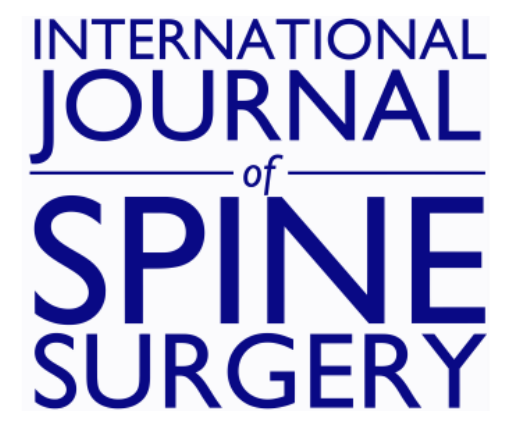

\title{
A Rare Case of T1-2 Thoracic Disc Herniation Mimicking Cervical Radiculopathy
}

H. Bahadir Gokcen, Sinan Erdogan, Gurkan Gumussuyu, Sidar Ozturk and Cagatay Ozturk

Int J Spine Surg 2017, 11 (4)

doi: https://doi.org/10.14444/4030

http://ijssurgery.com/content/11/4/30

This information is current as of April 26, 2023.

Email Alerts Receive free email-alerts when new articles cite this article. Sign up at:

http://ijssurgery.com/alerts

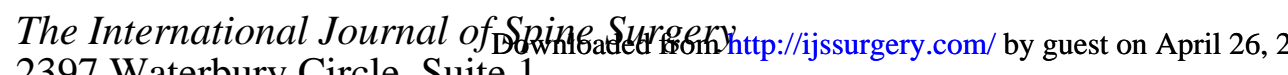
2397 Waterbury Circle, Suite 1,

Aurora, IL 60504, Phone: +1-630-375-1432

(C) 2017 ISASS. All Rights Reserved. 


\section{A Rare Case of T1-2 Thoracic Disc Herniation Mimicking Cervical Radiculopathy}

H. Bahadir Gokcen, MD, ${ }^{1}$ Sinan Erdogan, MD, ${ }^{1}$ Gurkan Gumussuyu, MD, ${ }^{2}$ Sidar Ozturk, MD, ${ }^{2}$ Cagatay Ozturk ${ }^{3}$

${ }^{1}$ Istinye University, Istanbul, Turkey, ${ }^{2}$ Medicalpark Hospital, Istanbul, Turkey, ${ }^{3}$ LIV Hospital LIV Spine Center. Istanbul, Turkey

\section{Abstract}

Introduction

Thoracic disc herniation is not as common as other disc herniations seen at other levels of spinal column. Th1-Th2 disc herniation is an extremely rare condition. Physical and cautious radiological examination is significantly important for diagnosis.

\section{Case Presentation}

We report a 45 years old male case with complaint of neck pain radiating to right upper extremity. The physical examination revealed Th1 radiculopathy symptoms. According to his images degeneration at C6-7 level and right T1 root compression due to Th1-Th2 disc herniation at foraminal region were evaluated. The patient underwent hemilaminectomy, foraminatomy and discectomy at T1-T2 level via posterior approach.

\section{Conclusion}

T1-2 level thoracic disc herniation can accompany with cervical region problems and some syndromes can mimic Th1 radiculopathy symptoms. The aim of this case report is to keep on mind of this rare condition and to emphasize the importance of physical findings and correlations with magnetic resonance imaging.

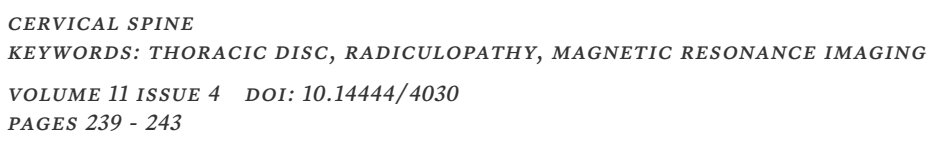

\section{Introduction}

Thoracic disc herniations are rare conditions compared with other disc herniations seen at cervical and lumbar spine levels. Approximately $75 \%$ of all thoracic disc herniations are seen below $\mathrm{T} 8 .^{1-3}$ The most affected area in the thoracic region is the T11-12 level. ${ }^{4,5}$ The first T1-2 disc herniation case was reported in 1954 by Sivien and Karavitis. ${ }^{6}$ Approximately more than $70 \%$ of thoracic disc herniations are asymptomatic. The incidence of symptomatic thoracic disc herniations is $1 / 1.000 .000$ per year and they are usually seen at levels $\mathrm{T} 8-11 .^{7-9}$ The case is here reported of a patient with T1-2 disc herniation presenting with T1 radiculopathy.

\section{Case Report}

A 45-year old male was admitted to our hospital with the complaint of neck pain radiating to the right upper extremity, and numbness in the medial arm, fourth and fifth fingers, which had been ongoing for two months. Physical examination revealed right medial arm and hand paresthesia, and motor weakness of the intrinsic muscles of the hand at grade 4/5. Upper extremity reflexes were normal. No pathological reflexes and no myelopathic symptoms were evaluated. Magnetic resonance imaging (MRI) of the cervi$\mathrm{cal}$ and thoracic region was applied. Degeneration was seen at C6-7 level and right $\mathrm{T} 1$ root compression due to Th1-Th2 disc herniation in the foraminal region (Figure 1, Figure 2, Figure 3, and Figure 4). In the physical examination, the findings of the complaints of the patient were related with T1 radiculopathy due to T1-2 disc herniation. Surgical treatment via posterior approach was planned. In this case costotransversectomy, hemilaminectomy, foraminatomy and discectomy at T1-2 level were performed via a posterior approach. Approximately 3 to $4 \mathrm{~cm}$ of rib was resected to provide an angle to see the disc space without retracting the spinal cord. Also the facet joint on the right side was resected close to the totally and nerve root exposure was performed. After the discectomy bleeding control was 
done and drain was placed which was taken 1 day after the surgery. The pain radiating to the right upper extremity decreased significantly in the first 3 hours after surgical decompression and removal of the disc fragment (Figure 5). The patient made a complete recovery by 3 months postoperatively. Total hospital stay was 3 days. Total follow-up of the patient was 1 year and there was no complication during surgery, hospitalization and follow-up period.

\section{Discussion}

Most thoracic disc herniations are asymptomatic. ${ }^{7}$ The clinical presentation of patients varies related to the level of disc herniation. Pain is the most common presentation and is usually located at the thoracic spine level with radiation in a radicular distribution. Other physical findings are unilateral or bilateral sensory loss, weakness of muscles, and bladder or bowel dysfunctions according to the affected level. ${ }^{10} \mathrm{~T} 1-2$ disc herniation is a more rare condition and can be seen with degenerative conditions or adjacent segment disease related to cervical fusion surgery. ${ }^{11}$ In the literature it has been reported following cervical laminoplasty and explained as mechanical stresses which may have directly affected the T1-2 interverte-

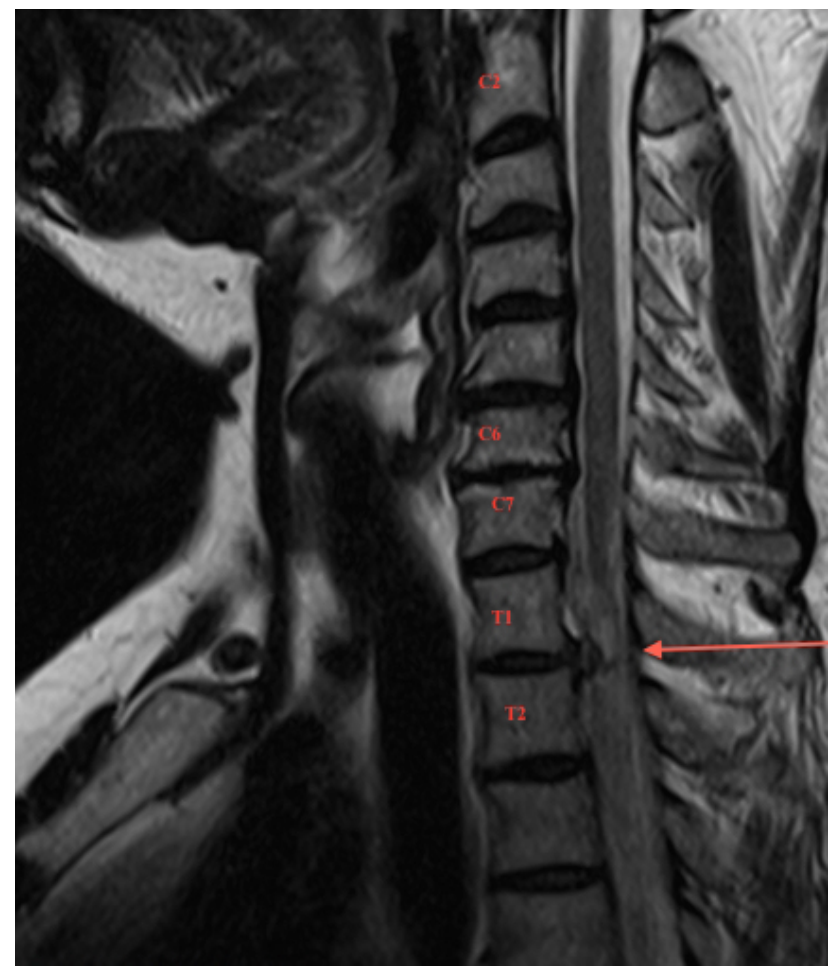

Fig. 1. bral disc following laminoplasty and may have caused disc herniation. ${ }^{12}$ MRI, CT or myelography may be used for diagnosis. MRI is the preferred diagnosis method because of its non-invasive, high soft tissue resolution and multi-planar imaging capability features. Radiological examination must be done cautiously. The thoracic region is at the caudal end of the cervical MRI, and it is important not to miss thoracic disc herniation in this region. In literature there

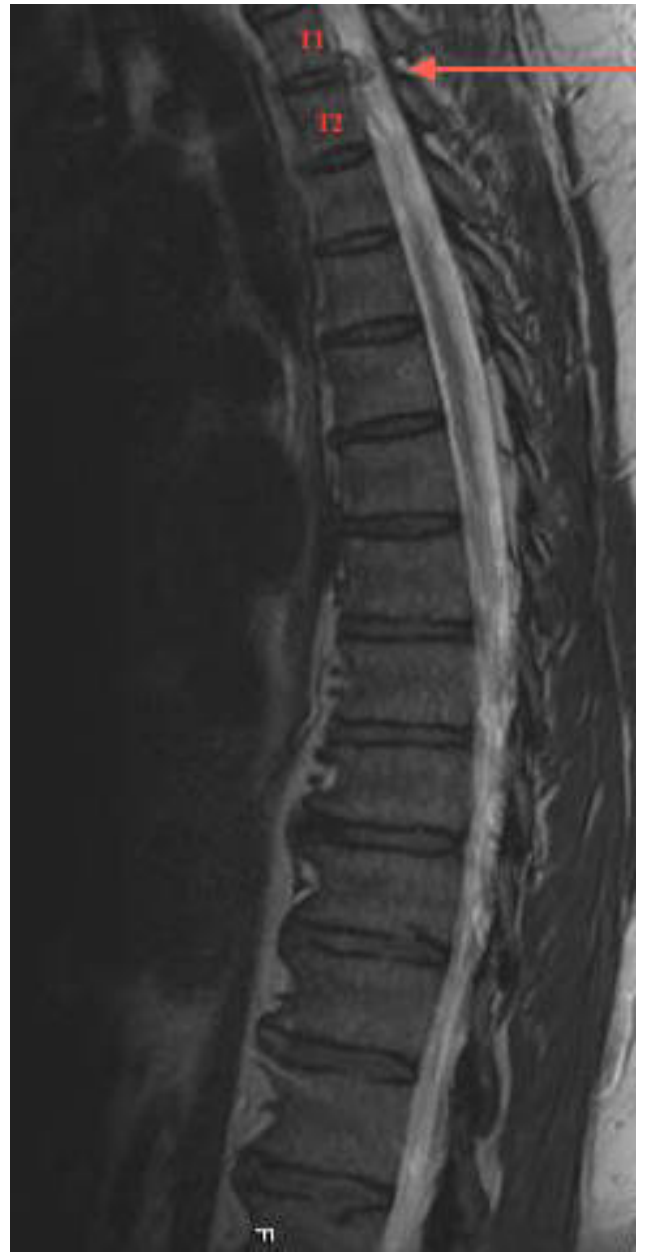

Fig. 2.

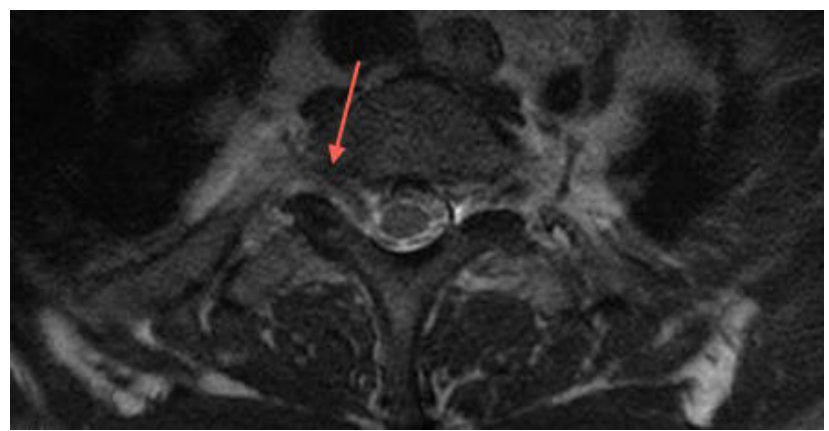

Fig. 3. 
is one case reported with T1-2 disc herniation, which was assumed to be cervical disc disease on first radiological assessment with physical findings. ${ }^{13}$ Detailed and careful physical examination is just as important as radiological evaluation. T1 radiculopathy may be accompanied by $\mathrm{C} 8$ radiculopathy symptoms. Numbness of the fourth and fifth fingers or weakness of intrinsic muscles in the hand are accompanying symptoms with $\mathrm{C} 8$ and $\mathrm{T} 1$ radiculopathy. Cubital tunnel syndrome and Guyon's tunnel syndrome may mimic the symptoms of T1 radiculopathy. In literature, Horner's syndrome has also been reported secondary to T1-2 disc herniation. ${ }^{14,15}$

It has also been reported that spine surgeons who consider themselves experts in cervical spine surgery may have inadequate knowledge of C8 and $\mathrm{T} 1 \mathrm{my}-$ otomes and dermatomes and may correctly identify the intrinsic hand muscles that are innervated by the C8-T1 nerve roots but not the ulnar nerve. The ulnar nerve provides sensation to the fourth and fifth fin-

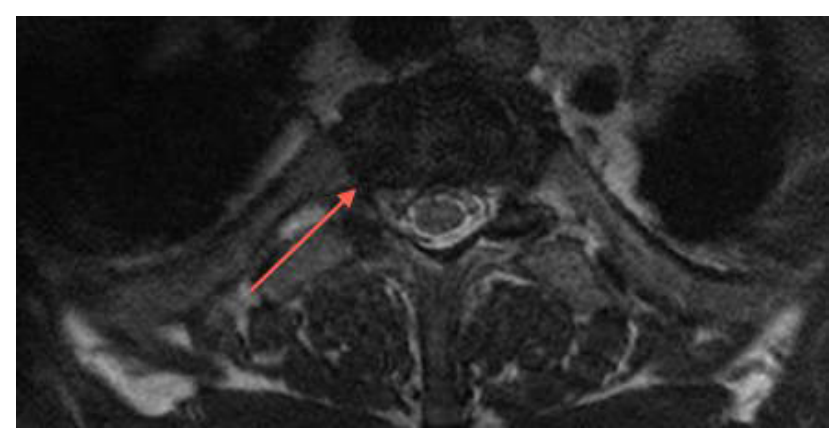

Fig. 4.

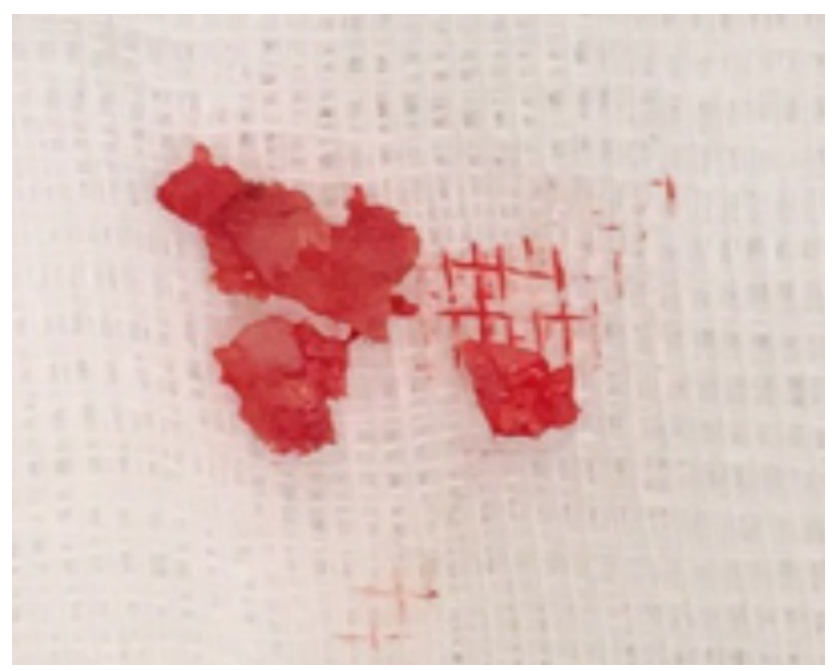

Fig. 5. gers and medial border of the hand. The medial antebrachial cutaneous nerve provides sensation to the medial forearm. The ulnar nerve innervates all intrinsic hand muscles, except the abductor and flexor pollicis brevis, opponens pollicis, and lateral two lumbricals, which are innervated by $\mathrm{C} 8$ and $\mathrm{T} 1$ via the median nerve. By examining these five muscles, one can clinically differentiate cubital tunnel syndrome from C8-T1 radiculopathies. ${ }^{16}$ Electrodiagnostic studies may be useful in evaluating and differentiating $\mathrm{C} 8, \mathrm{~T} 1$ and ulnar neuropathy. The muscle groups associated with a $\mathrm{C} 8$ radiculopathy are the first dorsal interosseous, abductor digit minimi, abductor pollicis brevis, flexor pollicis longus, and extensor indicis proprius. ${ }^{17}$ The paraspinal musculature should be examined as well because they receive motor innervation from the ipsilateral dorsal rami of the exiting root which can be compressed only at the foramen and not in a peripheral neuropathy that asymptomatic patients can have EMG changes in the cervical paraspinals. ${ }^{18}$ Abductor pollicis brevis is predominantly innervated by the T1 nerve root level, EMG changes in this muscle indicates T1 neuropathy. ${ }^{19}$

The first step of the treatment algorithm for thoracic radiculopathy is non-operative management. Traction may be applied for temporary decompression of the nerve impingement. Pharmacotheraphy may help to resolve pain in patients with radiculopathy. Nonsteroidal anti-inflammatory drugs have been used by many physicians as first-line agents in the treatment of pain. Narcotic analgesics, muscle relaxants, antidepressants, or anticonvulsants may be used in addition to nonsteroidal anti-inflammatory drugs. In the literature opioids may be effective in the treatment of neuropathic pain. ${ }^{20,21}$ Physical therapy may improve life quality, and selective nerve blocks target nerve root pain. Steroid injections may be the treatment option of radicular pain. Perineural injections including trans-laminar and transforaminal epidurals, selective nerve root blocks may be performed under radiographic guidance. ${ }^{22,23}$ However, there is little highquality evidence on the best non-operative therapy for radiculopathy, although it has been reported that a multi- modal approach may alleviate symptoms. ${ }^{24}$ In the current case physical therapy and medication for pain were used but these conservative methods 
did not resolve the symptoms.

The second step for thoracic radiculopathy not responding to conservative treatment modalities is surgical treatment. Anterior, posterior or posterolateral approaches are the surgical treatment techniques for T1-2 disc herniation described in literature. ${ }^{7,25,26,27}$ Our preferred surgical technique in posterior thoracic discectomy is costotransversectomy and discectomy. In this case costotransversectomy, hemilaminectomy, foraminatomy and discectomy at T1-2 level were performed via posterior approach. It was considered better to get through the T1-2 foramen via the posterior approach, because with the anterior approach sternotomy may be required to reach the T1-2 disc level. ${ }^{26}$

T1-2 level thoracic disc herniation may be accompanied by cervical region problems and some syndromes can mimic T1 radiculopathy symptoms. Detailed physical examination is of critical importance to determine the real problem and affected level in the spine.

\section{Conclusion}

Thoracic disc herniations are rare conditions and T1-2 level disc herniations are extremely rare. Therefore, the physician should keep this rare condition in mind and evaluate the cervical and thoracic region with MRI in patients with T1-2 disc herniation symptoms.

\section{References}

1. Sekhar LN, Jannetta PJ. Thoracic disk herniation: operative approaches and results. Neurosurgery 1983;12:303-5.

2. Boriani S, Biagini R, De Lure F, P.Rocella, V.Veronesi, S.Dalbuono, M.Di FioreTwo-level thoracic disk herniation. Spine 1994;21:2461-6.

3. Okada Y, Shimizu K, Ido K, Kotani S. Multiple thoracic disk herniations: case report and review of the literature. Spinal Cord 1997;35:183-6.

4. Arseni C, Nash F. Thoracic intervertebral disc protrusion: a clinical study. J Neurosurg 1960;17:418-30.
5. Murphey F, Simmons JCH, Brunson B. Surgical treatment of laterally ruptured cervical disc: review of 648 cases, 1939 to 1972 . J Neurosurg 1973;38:679-83.

6. Svien HJ, Karavitis AL. Multiple protrusions of intervertebral disks in the upper thoracic region: report of case. Proc Staff Meet Mayo Clin 1954;29:375-8.

7. Arce CA, Dohrmann GJ. Herniated thoracic disks. Neurol Clin 1985;3:383-92.

8. Okada Y, Shimizu K, Ido K, Kotani S. Multiple thoracic disk herniations: case report and review of the literature. Spinal Cord 1997;35:183-6.

9. Wood KB, Garvey TA, Gundry C, Heithoff KB. Magnetic resonance imaging of the thoracic spine: evaluation of asymptomatic individuals. J Bone Joint Surg Am 1995;77:1631-8.

10. Ozturk C, Tezer M, Sirvanci M, Sarier M, Aydogan M, Hamzaoglu A. Far lateral thoracic disc herniation presenting with flank pain. The Spine Journal 2006;6:201-203.

11. Freccero, D. and Donovan, D.J. (2005) Adjacent Segment Degeneration at T1-T2 Presenting as Chest Pain: Case Report. Spine (Phila Pa 1976);30:655-657. 12. Takagi H1, Kawaguchi Y, Kanamori M, Abe Y, Kimura T. T1-2 disc herniation following an en bloc cervical laminoplasty. J Orthop Sci. 2002;7(4):495-7. 13. Son ES, Lee SH, Park SY, Kim KT, Kang CH, Cho SW. Surgical treatment of T1-2 disc herniation with T1 radiculopathy: a case report with review of the literature. Asian Spine J. 2012 Sep;6(3):199-202. 14. Lloyd TV, Johnson JC, Paul DJ, Hunt W. Horner's syndrome secondary to herniated disc at T1--T2. AJR Am J Roentgenol. 1980 Jan;134(1):184-5.

15. Spacey K, Zaidan A, Khazim R, Dannawi Z. Horner's syndrome secondary to intervertebral disc herniation at the level of T1-2. BMJ Case Rep. 2014 Jun $5 ; 2014$.

16. Stoker GE, Kim HJ, Riew KD. Differentiating c8-t1 radiculopathy from ulnar neuropathy: a survey of 24 spine surgeons. Global Spine J. 2014 Feb;4(1):1-6.

17. K.H. Levin, H.J. Maggiano, A.J. Wilbourn. Cervical radiculopathies: comparison of surgical and EMG localization of single-root lesions. Neurology, 46 (1996), pp. 1022-1025 
18. E.S. Date, B.J. Kim, J.S. Yoon, B.K. Park. Cervical paraspinal spontaneous activity in asymptomatic subjects. Muscle Nerve, 34 (2006), pp. 361-364 19. Radecki J1, Feinberg JH, Zimmer ZR. T1 radiculopathy: electrodiagnostic evaluation. HSS J. 2009 Feb;5(1):73-7.

20. Eisenberg E, McNicol E, Carr DB. Opioids for neuropathic pain. Cochrane Database Sys Rev. 2006;(3):CD006146.

21. Eisenberg E, McNicol ED, Carr DB. Efficacy and safety of opioid agonists in the treatment of neuropathic pain of nonmalignant origin: systematic review and meta-analysis of randomized controlled trials. JAMA. 2005;293(24):3043-3052.

22. Anderberg L1, Annertz M, Rydholm U, Brandt L, Säveland H. Selective diagnostic nerve root block for the evaluation of radicular pain in the multilevel degenerated cervical spine. Eur Spine J. 2006 Jun;15(6):794-801

23. Anderberg L, Annertz M, Persson L, Brandt L, Säveland H. Transforaminal steroid injections for the treatment of cervical radiculopathy: a prospective and randomised study. Eur Spine J.

2007;16(3):321-328.

24. Eubanks JD. Cervical Radiculopathy: Nonoperative Management of Neck Pain and Radicular
Symptoms. Am Fam Physician. 2010 Jan 1;81(1):33-40.

25. Morgan H, Abood C. Disc herniation at T1-2: report of four cases and literature review. J Neurosurg 1998;88:148-50.

26. Rossitti S, Stephensen H, Ekholm S, von Essen

C. The anterior approach to high thoracic (T1-T2)

disc herniation.Br J Neurosurg 1993;7:189-92.

27. Nakahara $S$, Sato T. First thoracic disc herniation with myelopathy. Eur Spine J. 1995;4(6):366-7.

\section{Disclosures \& COI}

The authors report no relevant disclosures.

\section{Corresponding Author}

H. Bahadır Gokcen, MD, Medicalpark Hospital, 34160 Bahcelievler, Istanbul, Turkey. bahadrgokcen@gmail.com.

Published 28 November 2017.

This manuscript is generously published free of charge by ISASS, the International Society for the Advancement of Spine Surgery. Copyright @ 2017 ISASS. To see more or order reprints or permissions, see http://ijssurgery.com. 